\title{
Using Yield Response Curves to Measure Variation in the Tolerance and Resistance of Wheat Cultivars to Fusarium Crown Rot
}

\author{
Clayton R. Forknall, ${ }^{1, \dagger}$ Steven Simpfendorfer, ${ }^{2}$ and Alison M. Kelly ${ }^{1}$ \\ ${ }^{1}$ Department of Agriculture and Fisheries, Leslie Research Facility, Toowoomba, Queensland 4350, Australia; and 2 New South Wales \\ Department of Primary Industries, Tamworth, New South Wales 2340, Australia \\ Accepted for publication 19 December 2018.
}

\begin{abstract}
The disease crown rot, caused predominantly by the fungal pathogen Fusarium pseudograminearum, is a major disease of winter cereals in many regions of the world, including Australia. A methodology is proposed, using response curves, to robustly estimate the relationship between grain yield and increasing crown rot pathogen burdens. Using data from a field experiment conducted in northern New South Wales, Australia in 2016, response curves were derived for five commercial wheat cultivars exposed to six increasing rates of crown rot inoculum, where the rates served to establish a range of crown rot pathogen burdens. In this way, the response curve methodology is fundamentally different from alternate approaches that rely on genetic or environmental variation to establish a range in pathogen burdens over which yield loss relationships are estimated. By manipulating only the rates of crown rot inoculum and, thus, pathogen burden directly, the number of additional confounding factors and interactions are minimized, enabling the
\end{abstract}

ABSTRAC

The disease crown rot, caused predominantly by the fungal pathogen Fusarium pseudograminearum, is a major disease of bread wheat (Triticum aestivum), durum wheat (T. turgidum), and barley (Hordeum vulgare) (Alahmad et al. 2018b). Crown rot was first identified in Queensland, Australia (McKnight and Hart 1966) and has subsequently been recognized as an important disease of winter cereals internationally, including in the United States (Smiley et al. 2005), South Africa (Lamprecht et al. 2006), Tunisia (Chekali et al. 2011), Turkey (Tunali et al. 2008), and, more recently, China (Li et al. 2012). Within Australia, crown rot occurs across all winter cereal-growing regions (Backhouse et al. 2004; Khangura et al. 2013), with an annual combined cost to the Australian wheat and barley industries estimated at \$97 million (Murray and Brennan 2009, 2010).

$F$. pseudograminearum has a wide range of winter cereal and grass hosts and survives as fungal hyphae in the residues of infected plants for extended periods (Summerell et al. 1990). The primary management option for the control of crown rot is the inclusion of noncereals in the crop rotation sequence (Evans et al. 2010; Kirkegaard et al. 2004), with the impact of the disease further minimized by the adoption of inter-row sowing practices; that is, the sowing of crops in the space between the rows of previous host crop residues (Verrell et al. 2017). These approaches use temporal and spatial shifts to limit contact between susceptible crops and sources of inoculum. Currently, only one fungicide product is registered for the suppression of crown rot in Australia; however, it has been

${ }^{\dagger}$ Corresponding author: C. Forknall; E-mail: clayton.forknall@daf.qld.gov.au

Funding: This research was made possible by the support of the Grains Research and Development Corporation.

The author(s) declare no conflict of interest.

(c) 2019 The American Phytopathological Society robust estimation of the rate of change in yield due to increasing crown rot pathogen burdens for each cultivar. The methodology revealed variation in the rate of change in yield between cultivars, along with the extent of crown rot symptoms expressed by the cultivars. Variation in the rate of change in yield between cultivars provides definitive evidence of differences in the tolerance of commercial Australian wheat cultivars to crown rot caused by F. pseudograminearum, while variation in the extent of crown rot symptoms signifies differences in the resistance of the cultivars to this disease. The response curve methodology also revealed variation in how the different mechanisms of tolerance and resistance act to limit yield losses due to crown rot for different cultivars.

Keywords: Fusarium pseudograminearum, random regression, Triticum aestivum.

shown to have limited efficacy in reducing yield loss from crown rot infection when used alone (Simpfendorfer 2016).

Genetic solutions to crown rot are also limited. In Australia, decisions made by industry regarding the selection of cultivars for use in the presence of crown rot are currently only based on the resistance of cultivars to the disease, with little information available about the tolerance of cultivars. Resistant cultivars decrease the visual severity of infection in the base of tillers and, hence, the quantity of the crown rot pathogen in the host and, subsequently, in the cropping system. Alternatively, tolerant cultivars improve or maintain levels of production in the presence of crown rot infection, compared with other cultivars. Prebreeding efforts in Australia are focused on developing cultivars with improved resistance and tolerance to crown rot (Kelly et al. 2016; Liu and Ogbonnaya 2015); however, it is challenging to partition resistance from tolerance using current methodologies (Kelly et al. 2016).

In the context of plant pathology, tolerance to disease is defined as the ability of a host to limit the damage or impact of a given pathogen burden on host health (Kause and Ødegård 2012). As such, a tolerant cultivar is defined as one that loses significantly less yield or quality compared with other cultivars, although withstanding an equivalent pathogen burden as the other cultivars (Schafer 1971; Smiley and Yan 2009; van den Berg et al. 2017). More formally, tolerance can be defined as the rate of change in yield or quality as pathogen burden increases (Råberg et al. 2009). Resistance to disease occurs when a host and pathogen are mutually incompatible and, as such, the host is able to prevent or limit the growth of the pathogen in a manner that reduces the impact of the pathogen on the host (Caldwell et al. 1958; Kause and Ødegård 2012). In this way, expression of resistance is different from tolerance.

Experiments to assess the tolerance of cultivars are often performed in the field, because reliable estimates of the grain yield of cultivars are required. Experimental techniques to measure tolerance require each cultivar to be exposed to a range of disease pressures, increasing in intensity from ideally no disease (nil 
disease control) through to a high disease pressure, with a sufficient number of intermediate disease pressures spanning the range between the two extremes (Råberg et al. 2009). Through exposure to these disease pressures, differential pathogen burdens develop for each cultivar, depending on the compatibility of the cultivar and pathogen. By measuring the yield and intensity of the pathogen burden or representative symptoms of the pathogen for each cultivar, the rate of change in yield due to disease can be estimated, where the rate of change in yield is synonymous with tolerance (Råberg et al. 2009; Simms 2000).

In the case of crown rot, differential disease pressures can be established by varying the concentration of inoculum to which experimental cultivars are exposed. Inoculation methods vary, with some inoculating experimental cultivar seed with spores (macroconidia) (Hollaway et al. 2013), while others incorporate sterilized grain colonized by $F$. pseudograminearum in the furrow with the seed of experimental cultivars at the time of sowing (Dodman and Wildermuth 1987). Cereal crop cultivars grown under these inoculated conditions become infected by the disease, and growth of the pathogen proliferates through the plant at a rate that is dependent on both environmental conditions and the resistance of the cultivar (Swan et al. 2000).

Crown rot infection can be characterized visually as a honeybrown discoloration at the base of infected tillers, with browning extending upward from the base of the tiller as the severity of the pathogen burden increases. Visual scoring systems based on the extent of stem browning have been adopted as the industry standard (Wallwork et al. 2004; Wildermuth and McNamara 1994), with ratings assigned according to the extent of complete or partial browning of the base of tillers. The intensity of the crown rot pathogen burden can also be measured directly through the use of quantitative polymerase chain reaction (qPCR) methods to quantify the fungal biomass of $F$. pseudograminearum in the stem of infected tillers (Hogg et al. 2007). Results from qPCR assays have been found to correspond well with visual ratings based on the severity of stem browning at the base of infected tillers (Hogg et al. 2007; Knight and Sutherland 2015). Both fungal biomass of $F$. pseudograminearum and the severity of stem browning have been demonstrated to be suitable estimates of crown rot pathogen burden (Hogg et al. 2007). Yield loss due to crown rot is partially determined by the formation of whiteheads or dead heads (McKnight and Hart 1966), which are induced by water stress during flowering and grain filling (Beddis and Burgess 1992; Chekali et al. 2011; Papendick and Cook 1974). These prematurely senesced spikes contain either no grain or shriveled grain, depending on the timing of stress relative to grain development. A recent study has demonstrated that tillers displaying greater severity of stem browning and F. pseudograminearum biomass more typically exhibit whiteheads (Knight et al. 2017).

Previous experimental methods to evaluate the tolerance of cultivars to plant diseases have varied, with some studies comparing the yield of cultivars exposed to a high, uniform disease pressure in the field and attributing yield differences between cultivars to differences in tolerance (Thompson et al. 1999; Trudgill 1991). However, without manipulating the disease pressures to which the cultivars are exposed, there can be no certainty that the observed yield differences between cultivars are due to differences in tolerance to disease. Rather, the observed yield differences could result from the differential response of cultivars to other unmeasured variables; for example, other pathogens, soil characteristics (salinity or nutrient deficiencies), or weather phenomena (frost or heat stress events) related to the environment in which the experiment was conducted (Simms 2000). Additionally, this approach cannot partition inherent differences in yield potential between cultivars in a given environment from tolerance.

Tolerance has also been quantified by comparing the difference or ratio between yield measured from field plots controlled to ensure that no pathogen is present (nil disease control) and the yield measured from plots in which high disease pressures have been applied or established (Smiley and Yan 2009; Trudgill 1991). The inclusion of a nil disease control in this method allows the yield potential of cultivars to be estimated and enables yield differences measured for a given cultivar, or on average across all cultivars, to be attributed to the manipulated experimental treatment; in this case, high disease pressure. To reliably attribute differences in yield to greater disease pressure, assessments of the pathogen burden need to be undertaken in both the disease-free and diseased plots; otherwise, misleading or biased estimates of the yield impact of the disease may be determined because, in reality, completely diseasefree plots are difficult to achieve (Kelly et al. 2016). Techniques to derive "tolerance-like" measures, referred to as yield responsiveness and yield advantage, from experiments conducted using paired diseased and disease-free plots have been developed (Kelly et al. 2016). However, with only two disease treatments, there is insufficient information to reliably estimate the rate of change in yield due to disease and, thus, tolerance of cultivars.

Response curves offer a means of modeling a relationship between yield and pathogen burden to describe yield losses due to disease. The simplest form of response curve can be derived by fitting a linear regression model for yield against pathogen burden for each cultivar. From the linear regression model, the estimate of the slope parameter quantifies the rate of change in yield per unit increase in pathogen burden, or tolerance, of a cultivar (Råberg et al. 2009; Simms 2000). The intercept parameter provides an estimate of the yield potential of the cultivar, which is the potential yield of the cultivar in that environment, grown in the absence of disease (Råberg et al. 2009). An alternative to the linear regression model is the random regression or random coefficients model which, in its simplest form, allows for the estimation of parameters from a standard regression model as random effects in a linear mixed model framework (Laird and Ware 1982). This approach enables the modeling of variation between the response of cultivars around an overall response profile (De Faveri et al. 2015). Additionally, this response profile can be extended to account for nonlinearity in the rate of change in yield due to disease.

The aims of this study were to (i) demonstrate the effectiveness of the response curve methodology for quantifying the yield response of wheat cultivars to the disease crown rot and (ii) explore how cultivars limit yield losses to this disease, in terms of both resistance and tolerance. A field experiment conducted in 2016 near Bullarah in northern New South Wales, Australia provides the motivating data set for the application of the response curve methodology.

\section{MATERIALS AND METHODS}

A field experiment located near Bullarah, New South Wales, Australia (S 29.54591, E 149.07883) was conducted in 2016 to assess the yield loss of wheat cultivars due to the disease crown rot.

The experiment consisted of four commercial Australian bread wheat cultivars (EGA Gregory, Lincoln, Sunguard, and Suntop) and one durum wheat cultivar (Caparoi), selected to have similar times to reach flowering from sowing, with a recommended sowing window of mid- to late May in northern New South Wales. Each cultivar was exposed to six rates of crown rot inoculum: $0,0.25,0.5,1.0,2.0$, and $4.0 \mathrm{~g}$ of inoculum per meter of row. The inoculum was applied at sowing (25 May 2016) using a modified version of the Dodman and Wildermuth (1987) method. Inoculum was prepared from durum grain sterilized by autoclaving at $121{ }^{\circ} \mathrm{C}$ for $60 \mathrm{~min}$ on two consecutive days. Macroconidial suspensions were initially prepared in mung bean broth (grown for 7 days) and were then used to inoculate separate batches of sterilized durum grain for each of five $F$. pseudograminearum isolates, where isolates were collected postharvest from experiments conducted in New South Wales, Queensland, and Victoria, Australia in 2015. The inoculated durum grain was then grown at $25^{\circ} \mathrm{C}$ for 3 weeks and air dried at $30^{\circ} \mathrm{C}$ before pooling the colonized grain into equal quantities of the five $F$. pseudograminearum isolates and packing with the viable cultivar seed prior to sowing. A mixture of isolates was used to ensure consistent aggressiveness of the inoculum. 
The treatments were randomized according to a split-plot design, where cultivars were allocated to main plots and the rates of inoculum were allocated to subplots, randomized within main plots. Three replicates of each treatment combination, being the combination of cultivar and applied inoculum rate, were included in the experiment, providing a total of 90 experimental plots $(n=90)$. These 90 plots were arranged in a rectangular spatial array of 15 rows by six columns in the field, with each replicate block consisting of 15 rows by two columns (Fig. 1). Experimental plots were $7.6 \mathrm{~m}$ in length and consisted of five rows of plants, spaced at $33 \mathrm{~cm}$, with a target planting density of 100 plants $/ \mathrm{m}^{2}$ for all cultivars based on 1,000 grain weight and percentage germination from seed testing assays prior to sowing.

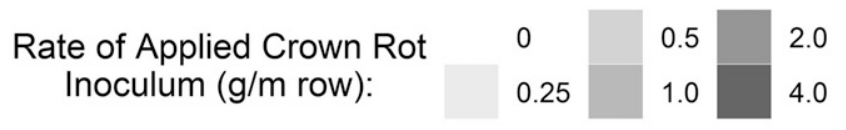

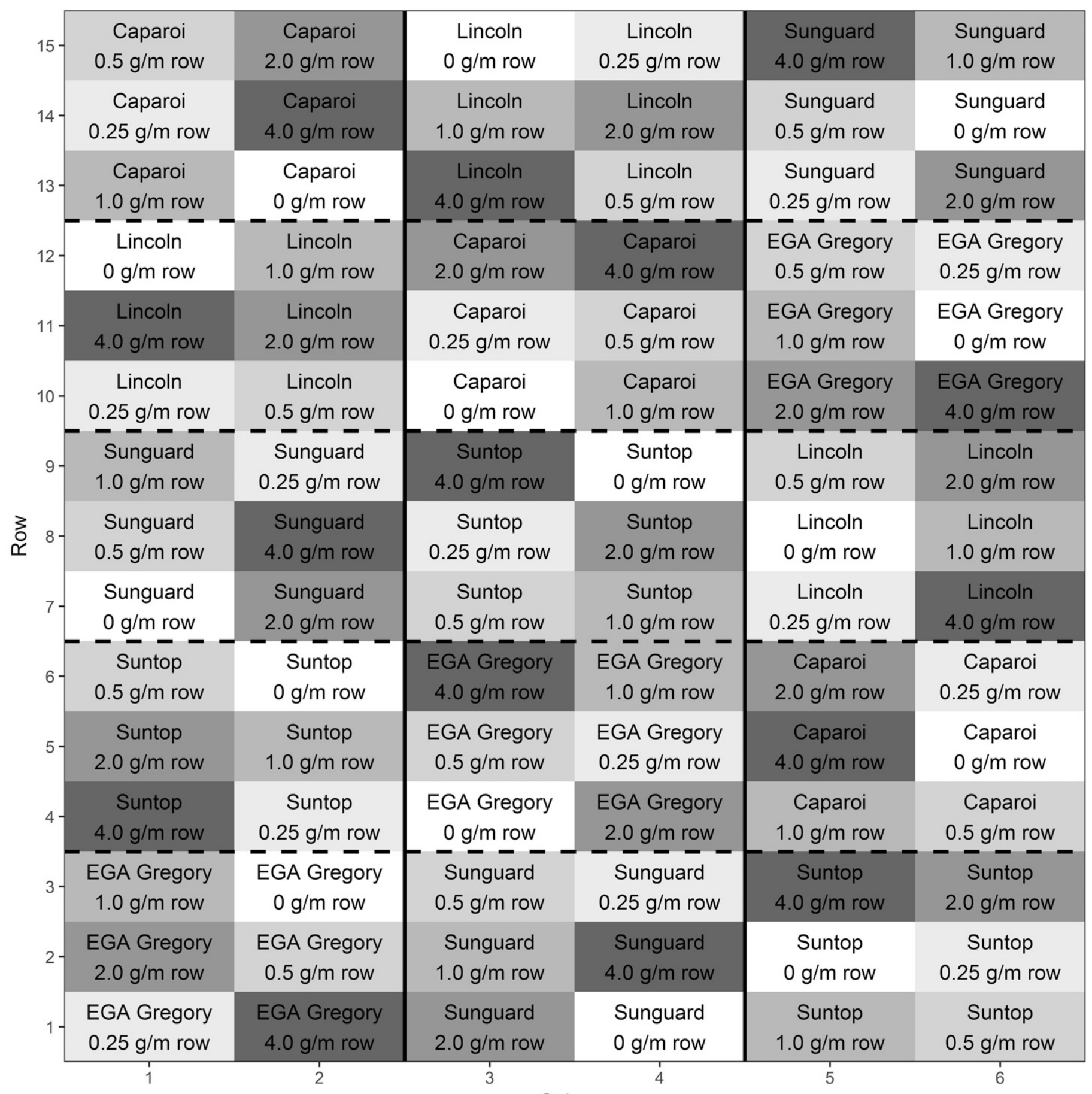

Column

Fig. 1. Layout of the treatments included in the experiment conducted near Bullarah in 2016. Dashed horizontal lines represent the main plot boundaries, while solid vertical lines correspond to replicate block boundaries. Shading of subplots corresponds to the differential rates of applied crown rot inoculum measured in grams of applied inoculum per meter of row ( $\mathrm{g} / \mathrm{m}$ row). 
Prior to sowing, separate bulk soil samples (30 soil cores, 0 to $15 \mathrm{~cm}$ in depth using a $10 \mathrm{~mm}$ diameter AccuCore) were collected randomly across each column of the experiment. PREDICTA B soil DNA tests (Ophel-Keller et al. 2008) were conducted on each bulked sample to determine the background concentration of $F$. pseudograminearum at the experimental location, along with levels of a range of other soilborne pathogens. The soil DNA tests revealed low estimated concentrations of $F$. pseudograminearum (F. pseudograminearum DNA at an average of $1.1 \pm 0.1 \mathrm{log} \mathrm{pg} / \mathrm{g}$ of soil) present at the location, persisting in the residues of previously infected crops. In addition, moderate populations of the plantparasitic nematode Pratylenchus thornei (average of $2.7 \pm 0.8$ nematodes/g of soil) were also identified across the location. None of the other soilborne pathogens assayed in the DNA tests (P. neglectus, Rhizoctonia solani, Bipolaris sorokiniana, Pythium clade $\mathrm{f}$, and Gaeumannomyces graminis var. tritici) were detected.

Grain yield was machine harvested (Kingaroy Engineering Works) and yield was measured on grain samples taken from each plot at maturity (8 December 2016).

A visual measure of crown rot symptoms based on the incidence and severity of browning of infected tillers was measured for 25 plants randomly sampled from the middle three rows of each five-row plot in the experiment, resulting in the collection and assessment of 2,250 individual plants. These plants were collected from plots by hand 4 days after harvest, with care taken to preserve the subcrown internode where possible. For each plant sampled, the total number of tillers on the plant along with the number of tillers that exhibited basal browning symptoms were recorded. By determining the number of tillers that exhibited basal browning from the total number of tillers, a measure of crown rot incidence was derived for each plant. The extent of browning symptoms averaged across all tillers on each plant was scored between 0 and 3 , increasing in 0.5 increments, where $0=$ no browning; $0.5=$ partial browning, 0 to $2 \mathrm{~cm} ; 1=$ complete browning, 0 to $2 \mathrm{~cm} ; 1.5=$ complete browning, 0 to $2 \mathrm{~cm}+$ partial browning, 2 to $4 \mathrm{~cm} ; 2=$ complete browning, 0 to $4 \mathrm{~cm} ; 2.5=$ complete browning, 0 to $4 \mathrm{~cm}+$ partial browning, 4 to $6 \mathrm{~cm}$; and $3=$ complete browning, 0 to $6 \mathrm{~cm}$ to provide a measure of crown rot severity for each plant.

The crown rot index was calculated for each plant, using the equation

Crown Rot Index $=[($ tillers with basal browning $/$

total number of tillers $) \times($ extent of basal browning $/ 3)] \times 100 \%$,

with the resulting crown rot index values ranging between $0 \%$ if no tillers on a plant displayed basal browning to $100 \%$ if all tillers on a plant displayed basal browning and this browning was complete from 0 to $6 \mathrm{~cm}$.

Response curves describing the relationship between yield and crown rot index for each cultivar $i$ (where $i=1,2, \ldots, v$ ) in the experiment were derived using a random regression model, implemented in a linear mixed model framework. This approach enabled the overall relationship between yield and crown rot index, labeled the yield response profile to disease, to be estimated using an $m$ th-order polynomial regression, while simultaneously modeling variation between the responses of the cultivars around this overall yield response profile. The general form of the linear mixed model fitted to the data can be written as:

$$
\boldsymbol{y}=\boldsymbol{X} \boldsymbol{\beta}+\boldsymbol{Z}_{\mathrm{g}} \boldsymbol{u}_{\mathrm{g}}+\boldsymbol{Z}_{\mathrm{p}} \boldsymbol{u}_{\mathrm{p}}+\boldsymbol{e}
$$

where $\boldsymbol{y}$ is an $n \times 1$ vector of yield observations measured on each plot, $\boldsymbol{\beta}=\left[\beta_{0}, \beta_{1}, \ldots, \beta_{m}\right]^{\mathrm{T}}$ is an $(m+1) \times 1$ vector of fixed effects corresponding to the coefficients of a polynomial regression of order $m$, and $\boldsymbol{X}=\left[\mathbf{1}_{n} \boldsymbol{X}_{\mathrm{c}}\right]$, where $\mathbf{1}_{n}$ is an $n \times 1$ vector of ones and $\boldsymbol{X}_{\mathrm{c}}$ is an $n \times m$ matrix of the form:

$$
\boldsymbol{X}_{\mathrm{c}}=\left[\begin{array}{cccc}
x_{1} & x_{1}^{2} & \cdots & x_{1}^{m} \\
\vdots & \vdots & & \vdots \\
x_{n} & x_{n}^{2} & \cdots & x_{n}^{m}
\end{array}\right]
$$

consisting of crown rot index observations measured on each plot and formed from the average of 25 individual plant values per plot.

The vector $\boldsymbol{u}_{\mathrm{g}}=\left[\boldsymbol{u}_{\mathrm{g}_{1}}^{\mathrm{T}}, \boldsymbol{u}_{\mathrm{g}_{2}}^{\mathrm{T}}, \ldots, \boldsymbol{u}_{\mathrm{g}_{v}}^{\mathrm{T}}\right]^{\mathrm{T}}$ is an $(m+1) v \times 1$ vector of random effects containing the coefficients of a polynomial regression of order $m$ for each cultivar $i$, where $\boldsymbol{u}_{\mathrm{g}_{i}}=\left[b_{0_{i}}, b_{1_{i}}, \ldots, b_{m_{i}}\right]^{\mathrm{T}}$. When observations are ordered by cultivar, the matrix $\boldsymbol{Z}_{\mathrm{g}}$ is of diagonal form, with dimension $n \times(m+1) v$ :

$$
\boldsymbol{Z}_{\mathrm{g}}=\operatorname{diag}\left(\boldsymbol{Z}_{\mathrm{g}_{i}}\right)=\left[\begin{array}{cccc}
\boldsymbol{Z}_{\mathrm{g}_{1}} & & & \\
\mathbf{0} & \boldsymbol{Z}_{\mathrm{g}_{2}} & & \\
\vdots & & \ddots & \\
\mathbf{0} & \mathbf{0} & \cdots & \boldsymbol{Z}_{\mathrm{g}_{v}}
\end{array}\right]
$$

where $\boldsymbol{Z}_{\mathrm{g}_{i}}=\left[\mathbf{1}_{n_{i}} \boldsymbol{X}_{\mathrm{c}_{i}}\right]$ and $\mathbf{1}_{n_{i}}$ is an $n_{i} \times 1$ vector of ones $\left(\sum n_{i}=n\right)$, while $\boldsymbol{X}_{\mathrm{c}_{i}}$ is an $n_{i} \times m$ matrix of crown rot index observations measured on each plot of cultivar $i$ :

$$
\boldsymbol{X}_{\mathrm{c}_{i}}=\left[\begin{array}{cccc}
x_{1_{i}} & x_{1_{i}}^{2} & \cdots & x_{1_{i}}^{m} \\
\vdots & \vdots & & \vdots \\
x_{n_{i}} & x_{n_{i}}^{2} & \cdots & x_{n_{i}}^{m}
\end{array}\right]
$$

Note that $\boldsymbol{X}_{\mathrm{c}}=\left[\begin{array}{c}\boldsymbol{X}_{\mathrm{c}_{i}} \\ \vdots \\ \boldsymbol{X}_{\mathrm{c}_{v}}\end{array}\right]$ when observations are ordered by cultivar. The vector $\boldsymbol{u}_{\mathrm{p}}$ contains random effects corresponding to the structure of the experimental design, including effects for replicate blocks and main plots within replicate blocks, with associated design matrix $\boldsymbol{Z}_{\mathrm{p}}$, and $\boldsymbol{e}$ is an $n \times 1$ vector of residual errors.

The random effects from the linear mixed model above are assumed to follow a normal distribution with zero mean vector and variance-covariance matrix:

$$
\operatorname{var}\left(\left[\begin{array}{c}
\boldsymbol{u}_{\mathrm{g}} \\
\boldsymbol{u}_{\mathrm{p}} \\
\boldsymbol{e}
\end{array}\right]\right)=\left[\begin{array}{ccc}
\boldsymbol{G}_{\mathrm{g}} & & \\
\mathbf{0} & \boldsymbol{G}_{\mathrm{p}} & \\
\mathbf{0} & \mathbf{0} & \boldsymbol{R}
\end{array}\right]
$$

Furthermore, the matrix $\boldsymbol{G}_{\mathrm{g}}$ can be written as:

$$
\boldsymbol{G}_{\mathrm{g}}=\boldsymbol{G}_{m} \otimes \boldsymbol{I}_{v}
$$

where $\boldsymbol{G}_{m}$ is an $(m+1) \times(m+1)$ symmetric matrix of unstructured form to ensure that the model remains invariant to translation (Fitzmaurice et al. 2008) and $\boldsymbol{I}_{v}$ is an identity matrix of dimension $v$.

Thus, the distribution of the data $\boldsymbol{y}$ is normal with mean $\boldsymbol{X} \boldsymbol{\beta}$ and variance:

$$
\operatorname{var}(\boldsymbol{y})=\boldsymbol{Z}_{\mathrm{g}} \boldsymbol{G}_{\mathrm{g}} \boldsymbol{Z}_{\mathrm{g}}^{\mathrm{T}}+\boldsymbol{Z}_{\mathrm{p}} \boldsymbol{G}_{\mathrm{p}} \boldsymbol{Z}_{\mathrm{p}}^{\mathrm{T}}+\boldsymbol{R}
$$

For the data arising from the experiment conducted near Bullarah in 2016, a first-order polynomial regression $(m=1)$ namely, a linear regression, was found to offer the most parsimonious description of the relationship between yield and crown rot index, in terms of the adequacy of model fit and number of parameters required. This simplifies the vectors $\boldsymbol{\beta}$ and $\boldsymbol{u}_{\mathrm{g}_{i}}$ to the following forms:

$$
\boldsymbol{\beta}=\left[\beta_{0}, \beta_{1}\right]^{\mathrm{T}} \text { and } \boldsymbol{u}_{\mathrm{g}_{i}}=\left[b_{0_{i}}, b_{1_{i}}\right]^{\mathrm{T}}
$$

where the parameters $\beta_{0}$ and $\beta_{1}$ correspond to the intercept and slope of the overall yield response profile, respectively, while $b_{0_{i}}$ 
and $b_{1_{i}}$ correspond to the random intercept and slope effects, respectively, where these effects are provided as deviations from the overall yield response profile for cultivar $i$.

Estimates of the overall linear response profile parameters $\left(\beta_{0}\right.$ and $\beta_{1}$ ) were provided from the model as empirical best linear unbiased estimators (e-BLUEs), while estimates of the random intercept $\left(b_{0_{i}}\right)$ and slope $\left(b_{1_{i}}\right)$ effects for each cultivar, were provided as empirical best linear unbiased predictors (e-BLUPs).

Predictions of the theoretical yield potential (intercept) and rate of change in yield due to disease (slope) for each cultivar were formed by combining the e-BLUEs of $\boldsymbol{\beta}(\hat{\boldsymbol{\beta}})$ and the e-BLUPs of $\boldsymbol{u}_{\mathrm{g}}\left(\widetilde{\boldsymbol{u}}_{\mathrm{g}}\right)$ as follows:

$$
\mathbf{1}_{v} \otimes \hat{\boldsymbol{\beta}}+\widetilde{\boldsymbol{u}}_{\mathrm{g}}
$$

where $\mathbf{1}_{v}$ is a $v \times 1$ vector of ones. The predicted intercepts for the cultivars were considered to be theoretical yield potentials due to the difficulties associated with establishing a true nil disease control treatment in practice and the limitation of having to extrapolate beyond the range of the observed data to estimate these effects.

All variance components were estimated using residual maximum likelihood (Patterson and Thompson 1971), implemented through the ASReml-R package (Butler et al. 2009) in the R statistical computing environment (R Core Team 2017).

\section{RESULTS}

The experiment conducted near Bullarah in 2016 enabled the yield response of five wheat cultivars to crown rot to be assessed. No crown rot inoculum was applied to some experimental plots in an attempt to achieve a nil disease control treatment. However, residues from previously infected host crops were present at the experimental location and resulted in low levels of infection in the bread wheat cultivars and moderate levels of infection in the durum wheat cultivar, Caparoi (Fig. 2). This is reflected in a comparison of the minimum crown rot index values exhibited by the cultivars, whereby Caparoi expressed a minimum value of $22.7 \%$, while the minimum crown rot index values measured on the four bread wheat cultivars ranged from 3.6 to $5.2 \%$ (Fig. 2). The median crown rot index values measured for each cultivar under each rate of applied inoculum varied (Fig. 2). The cultivar Caparoi consistently exhibited the highest median crown rot index values under each of the applied rates of inoculum (Fig. 2), implying a lack of resistance to crown rot. Conversely, the cultivar Sunguard consistently exhibited the lowest median crown rot index values under each of the rates of applied inoculum (Fig. 2), demonstrating the greatest resistance to crown rot of the cultivars considered.

Due to the difficulty in establishing a nil disease control treatment in the experiment, extrapolation beyond the range of the observed crown rot index values was required to estimate the yield of the cultivars in the absence of disease (crown rot index of $0 \%$ ). Thus, estimates of the yield potential are reported as theoretical and assume that the linear relationship estimated for each cultivar is consistent beyond the range of the observed values. The bread wheat cultivar Suntop was estimated to have the highest theoretical yield potential $(5.47 \mathrm{t} / \mathrm{ha})$ of all five wheat cultivars considered in the experiment, while the durum wheat cultivar Caparoi was estimated to have the lowest theoretical yield potential ( $4.96 \mathrm{t} / \mathrm{ha})$ in the environment (Table 1).

All five cultivars displayed a negative rate of change in yield as the crown rot pathogen burden increased; however, the magnitude of the rate of change varied between cultivars (Fig. 3; Table 1). The cultivar Suntop exhibited the highest median crown rot index value of the four bread wheat cultivars $(55.7 \%)$ (Fig. 2); however, it demonstrated the smallest rate of change in yield and, thus, greatest tolerance to crown rot of the cultivars considered (Fig. 3; Table 1). Therefore, under the environmental conditions experienced during the conduct of this experiment, the expected reduction in yield per unit increase in crown rot index of the cultivar Suntop was approximately $0.013 \mathrm{t} / \mathrm{ha}$ (Table 1 ). Conversely, the greatest rates of change in yield to crown rot, implying reduced tolerance to the disease, were exhibited by the cultivars Sunguard, Lincoln, and EGA Gregory (Fig. 3; Table 1). All three cultivars displayed similar rates of change in yield, with the expected reduction in yield per unit increase in crown rot index of the cultivars estimated to be between approximately 0.023 and 0.030 t/ha (Table 1); approximately two times the magnitude of the rate of change in yield demonstrated by Suntop. The durum wheat cultivar Caparoi displayed a rate of change in yield similar to Suntop (Table 1); however, this estimate was influenced by the inability to establish a near nil disease control for this cultivar due to its lack of resistance to the disease. Thus, the assessment of the rate of change in yield at lower levels of crown rot pathogen burden was not possible for this cultivar (Fig. 3).

Of the five wheat cultivars, the bread wheat cultivar Suntop was estimated to have the highest predicted minimum yield (4.68 t/ha); that is, the predicted yield under the maximum crown rot pathogen burden observed (Table 2). The cultivars Caparoi and Lincoln exhibited the lowest predicted minimum yields of 3.91 and 3.94 t/ha, respectively (Table 2).

\section{DISCUSSION}

The response curve methodology revealed that each of the five wheat cultivars in the 2016 Bullarah experiment exhibited a negative rate of change in yield under increasing crown rot pathogen burdens; however, the magnitude of the rates of change varied between the cultivars (Fig. 3; Table 1). Tolerance is defined as the rate of change in yield as pathogen burden increases (Råberg et al. 2009; Simms 2000); thus, variation in the rate of change in yield of the cultivars in the 2016 Bullarah experiment demonstrates variation in the tolerance of these cultivars to F. pseudograminearum. Previous studies have implied the ability to screen and select cultivars that display greater tolerance to crown rot (Alahmad et al. 2018a; Liu et al. 2012); however, the methods presented only enable assessment of resistance to this disease. The method of Alahmad et al. (2018a) was based solely on the visual assessment of the severity of basal browning 63 days after sowing under glasshouse conditions, while Liu et al. (2012) used a molecular approach to measure fungal biomass over time for a maximum of 35 days in glasshouse inoculated seedlings. Neither study involved any measure of yield and both are examples of how the term tolerance is often misused and inappropriately interchanged with the term resistance when describing studies of Fusarium crown rot. Given the definition of tolerance as the rate of change in yield as pathogen burden increases (Råberg et al. 2009; Simms 2000), this study provides the first set of definitive results demonstrating variation in the tolerance of commercial Australian wheat cultivars to the disease crown rot.

Although all cultivars displayed yield losses due to $F$. pseudograminearum, Suntop displayed the most tolerance to the pathogen, because the cultivar exhibited the smallest rate of change in yield (Fig. 3; Table 1). Conversely, Sunguard, Lincoln, and EGA Gregory demonstrated the least tolerance to the pathogen, with the three cultivars displaying similar rates of change that were approximately two times greater than those displayed by the most tolerant cultivar in the experiment (Table 1). The durum wheat cultivar Caparoi exhibited a level of tolerance similar to that of Suntop; however, the ability to estimate the rate of change in yield at low levels of pathogen burden was impeded by moderate levels of infection occurring when no or low levels of inoculum were applied (Fig. 2), due to residues of previously infected crops persisting at the experimental location. Therefore, the reported estimate of the rate of change in yield should be regarded as conservative for this durum wheat cultivar.

The response curve methodology also demonstrated variation in the resistance of the cultivars in the 2016 Bullarah experiment. 
Cultivars that possess resistance to crown rot will display less stem browning symptoms, leading to reduced crown rot index values compared with other, more susceptible, cultivars (Wallwork et al. 2004; Wildermuth and McNamara 1994). Of the bread wheat cultivars in the experiment, Sunguard demonstrated the greatest resistance to $F$. pseudograminearum by consistently displaying a lower median crown rot index value than the other cultivars under each of the applied rates of inoculum (Fig. 2). However, although demonstrating the greatest resistance to $F$. pseudograminearum in this experiment, the cultivar Sunguard is regarded by industry to be only "moderately susceptible" to the disease (Lush 2018). There are currently no commercial cultivars that display high levels of
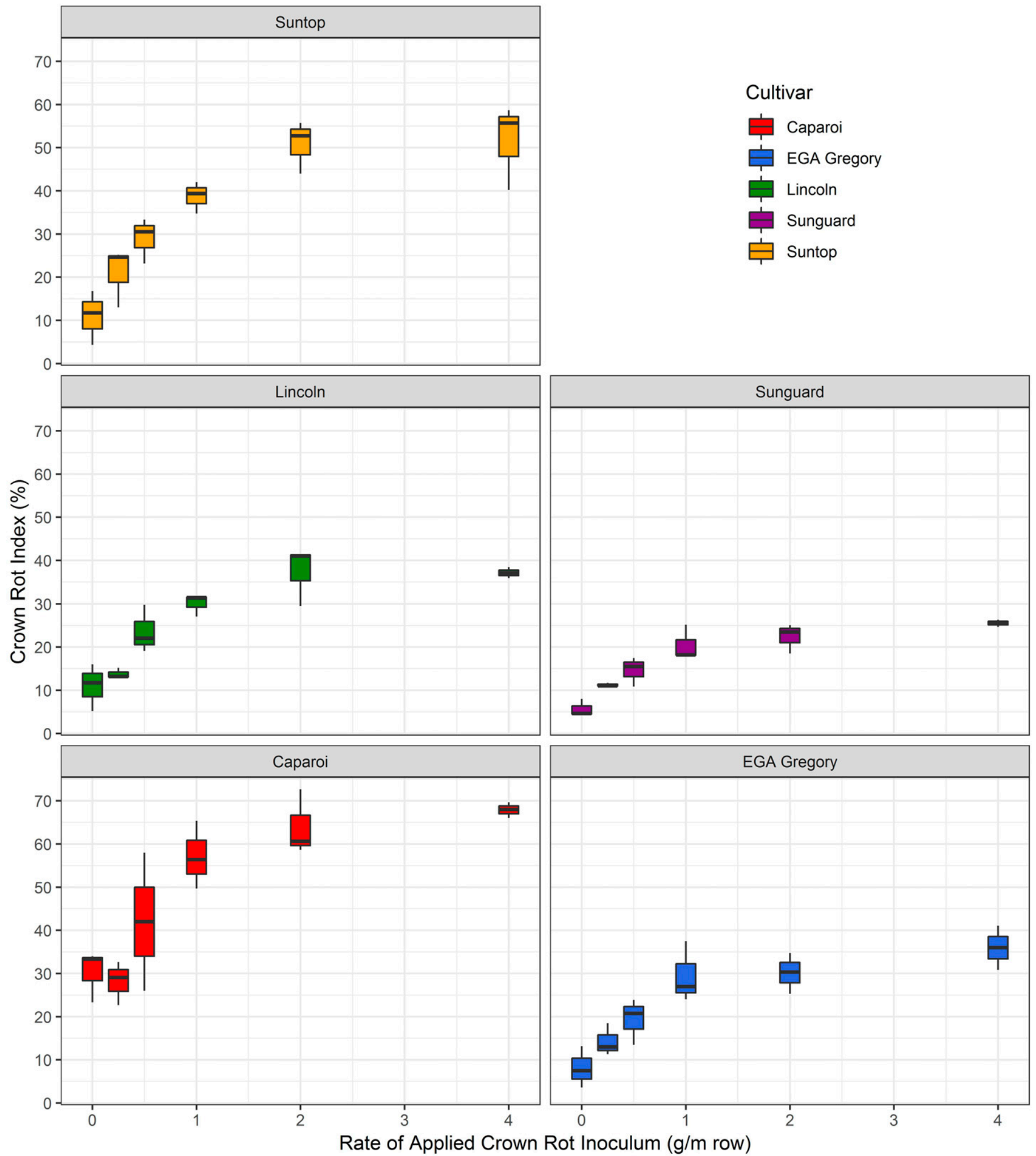

Fig. 2. Distribution of the crown rot index values measured on a plot basis for each of five wheat cultivars in the experiment conducted near Bullarah in 2016. Data are presented for each of the six rates of applied crown rot inoculum in the experiment, where the rates range from no applied inoculum (0) to $4.0 \mathrm{~g}$ of applied inoculum per meter of row. Shaded portions of boxes correspond to interquartile range, or range within which 50\% of observations lie, while thick black lines within each box denote the median of observations. Thin black vertical lines external to each box present the range of minimum and maximum values observed. 
resistance to F. pseudograminearum. Of the bread wheat cultivars in the experiment, Suntop exhibited the least resistance to the disease, displaying consistently higher crown rot index values than the other bread wheat cultivars across each of the applied rates of inoculum (Fig. 2). The range of crown rot index values exhibited by the cultivars EGA Gregory and Lincoln varied across the different rates of applied inoculum, with both cultivars showing near to equivalent levels of resistance to $F$. pseudograminearum. The durum wheat cultivar Caparoi displayed the least resistance to the disease by consistently exhibiting higher crown rot index values than the bread wheat cultivars under each of the applied rates of inoculum (Fig. 2). This result is consistent with the widely reported lack of resistance that durum wheat exhibits to crown rot, when compared with bread wheat (Hollaway et al. 2013; Knight and Sutherland 2015; Knight et al. 2017; Martin et al. 2013).

Response curves also provide a means of investigating how the different mechanisms of tolerance and resistance act to limit the extent of yield loss of cultivars to disease; for two equally resistant cultivars, tolerance limits the rate of yield loss under increasing pathogen burdens whereas, for two equally tolerant cultivars, resistance limits the extent to which pathogen burden can develop, potentially truncating the extent of yield losses at a level lower than that of a less resistant cultivar. In the 2016 Bullarah experiment, the cultivars Suntop and Sunguard provide a contrast in terms of the mechanisms used to limit yield losses to crown rot. Suntop was found to be the most tolerant cultivar in the experiment; however, it was also the least resistant of the bread wheat cultivars. Therefore, although exhibiting greater levels of crown rot symptoms, the cultivar was able to endure the pathogen burden and limit the extent of yield loss incurred (Fig. 3). Conversely, Sunguard was the most resistant cultivar in the experiment; however, it displayed the least tolerance to the disease. Although the yield loss of Sunguard per unit increase in pathogen burden was greater than two times that of Suntop, the extent of pathogen burden development was limited by

TABLE 1. Empirical best linear unbiased predictors of the theoretical yield potential and rate of change in yield of the five wheat cultivars included in the experiment conducted near Bullarah in 2016 and empirical best linear unbiased estimators of the parameters of the overall yield response profile ${ }^{a}$

\begin{tabular}{lcc}
\hline Cultivar & $\begin{array}{c}\text { Theoretical yield } \\
\text { potential }(\mathrm{t} / \mathrm{ha}) \pm \text { E.S.E. }\end{array}$ & $\begin{array}{c}\text { Rate of change in } \\
\text { yield }(\mathrm{t} / \mathrm{ha} \text { per unit } \\
\text { crown rot index }) \pm \text { E.S.E. }\end{array}$ \\
\hline Caparoi & $4.96 \pm 0.176$ & $-0.015 \pm 0.003$ \\
EGA Gregory & $5.29 \pm 0.166$ & $-0.023 \pm 0.004$ \\
Lincoln & $5.16 \pm 0.168$ & $-0.029 \pm 0.004$ \\
Sunguard & $5.33 \pm 0.165$ & $-0.030 \pm 0.005$ \\
Suntop & $5.47 \pm 0.165$ & $-0.013 \pm 0.003$ \\
Overall yield & & \\
$\quad$ response profile & $5.24 \pm 0.151$ & $-0.022 \pm 0.004$
\end{tabular}

a Theoretical yield potential is measured in tons per hectare $(\mathrm{t} / \mathrm{ha})$ and rate of change in yield is measured in $t /$ ha per unit change in crown rot index. E.S.E. = estimated standard error of the parameter estimates.

TABLE 2. Maximum observed crown rot index and predicted minimum yield of each of the five wheat cultivars included in the experiment conducted near Bullarah in 2016

\begin{tabular}{lcc}
\hline Cultivar & $\begin{array}{c}\text { Maximum observed } \\
\text { crown rot index }(\%)\end{array}$ & $\begin{array}{c}\text { Predicted minimum } \\
\text { yield (t/ha) } \pm \text { E.S.E. }\end{array}$ \\
\hline Caparoi & 72.7 & $3.91 \pm 0.170$ \\
EGA Gregory & 41.1 & $4.33 \pm 0.172$ \\
Lincoln & 41.4 & $3.94 \pm 0.169$ \\
Sunguard & 26.3 & $4.55 \pm 0.161$ \\
Suntop & 58.7 & $4.68 \pm 0.170$ \\
\hline
\end{tabular}

a Predicted minimum yield corresponds to the yield of a cultivar under the maximum observed crown rot pathogen burden exhibited by that cultivar. Predictions were formed using the estimated response curve for each cultivar. E.S.E. = estimated standard error of the prediction. the greater resistance of the cultivar (Fig. 3). In this experiment, the predicted minimum yields of Suntop and Sunguard (Table 2) were found to be similar, demonstrating how the different mechanisms of tolerance and resistance can act in different cultivars to limit the extent of yield loss due to crown rot.

A limitation of the experiment conducted at Bullarah in 2016 was the concentration of $F$. pseudograminearum pathogen persisting in the residues of previously infected crops at the experimental location. Although PREDICTA B soil DNA tests (Ophel-Keller et al.2008) prior to sowing revealed that the pathogen was estimated to be present in low concentrations (F. pseudograminearum DNA at an average of $1.1 \pm 0.1 \mathrm{log} \mathrm{pg} / \mathrm{g}$ of soil), there was still a sufficient quantity of the pathogen to result in moderate levels of infection in the least resistant durum wheat cultivar, Caparoi, when no additional inoculum was applied to the experimental plots. These moderate levels of infection resulted in the inability to measure the rate of change in yield of the cultivar at low levels of pathogen burden, thus potentially resulting in the underestimation of the rate of change in yield of this cultivar to crown rot. In addition, the soil DNA tests indicated that a moderate population (average of $2.7 \pm 0.8$ nematodes $/ g$ of soil) of the plant-parasitic nematode $P$. thornei was present at the experimental location. $P$. thornei are widespread across the northern grain-growing region of Australia and have been found to induce yield losses of up to $70 \%$ in intolerant wheat cultivars (Thompson et al. 2008, 2010). Of the five wheat cultivars included in the experiment in 2016, Lincoln is considered intolerant to $P$. thorne $i$ while the other cultivars are all considered moderately tolerant (Lush 2018). Therefore, the yield potential of Lincoln may have been negatively impacted by the presence of $P$. thornei across the experimental location. Furthermore, little is known about the interaction of $F$. pseudograminearum and $P$. thorne $i$ when coinfecting cereal plants in the field, which could serve to exacerbate the yield losses incurred. Although it poses a significant challenge for field-based experimentation, this demonstrates the need to establish uniform experimental conditions free from both preexisting levels of the target pathogen and other nontarget pathogens when conducting any experiment with the aim of quantifying the impact of a target pathogen on yield or any trait of interest.

The yield response methodology, demonstrated using the Bullarah 2016 experiment, provides a methodology for the robust estimation of the rate of change in yield as pathogen burden increases, interpreted as tolerance, of a series of cultivars. The method is distinctly different from alternate approaches used to quantify "tolerance-like" measures, where cultivars are either exposed to consistent, high disease pressures or paired treatments are applied in which one treatment is managed to be pathogen free while the other is under high disease pressure (Trudgill 1991). By exposing cultivars to consistent, high disease pressures, there can be no certainty that measured yield differences between cultivars are due to differences in tolerance to the disease (as some studies conclude) (Thompson et al. 1999; Trudgill 1991), because the differences may also arise from inherent differences in the yield potential of the cultivars or cultivar-specific responses to other unmeasured variables in the environment in which the experiment was conducted. In experiments where paired high disease pressure and pathogen-free treatments are established, the yield potential of cultivars can be estimated from the pathogen-free treatments and yield losses due to the disease on a cultivar basis or other tolerance-like measures quantified (Kelly et al. 2016). However, by exposing cultivars to only two disease pressures, there is insufficient information to reliably estimate the rate of change in yield and, thus, tolerance to disease of the cultivars. Only through the manipulation and establishment of a range of differential disease pressures to which each cultivar is exposed and in which differential pathogen burdens develop can relationships capturing the yield response of cultivars to the pathogen be derived. Furthermore, using the definition of tolerance as the rate of change in yield or quality as pathogen burden increases (Råberg et al. 2009), only yield response relationships estimated using this methodology will provide a measure of tolerance to disease. 
This study considers results from a single experiment; however, future work will explore the impact of different environments on the level of tolerance and resistance displayed by cultivars to crown rot. Experiments similar to that conducted at Bullarah in 2016 have been performed across Australia from 2014 to 2018, using sets of regionally specific and commercially relevant cultivars, to explore the mechanisms of tolerance and resistance to crown rot and their interactions with environmental conditions.

\section{CONCLUSIONS}

The yield response methodology, as applied to the 2016 Bullarah experiment, provides the first set of definitive results demonstrating variation in the tolerance of commercial Australian wheat cultivars to crown rot caused by $F$. pseudograminearum, with the cultivar Suntop displaying a greater level of tolerance compared with the other cultivars in the experiment. Variation in tolerance to crown rot demonstrates the potential to explore genetic solutions to the

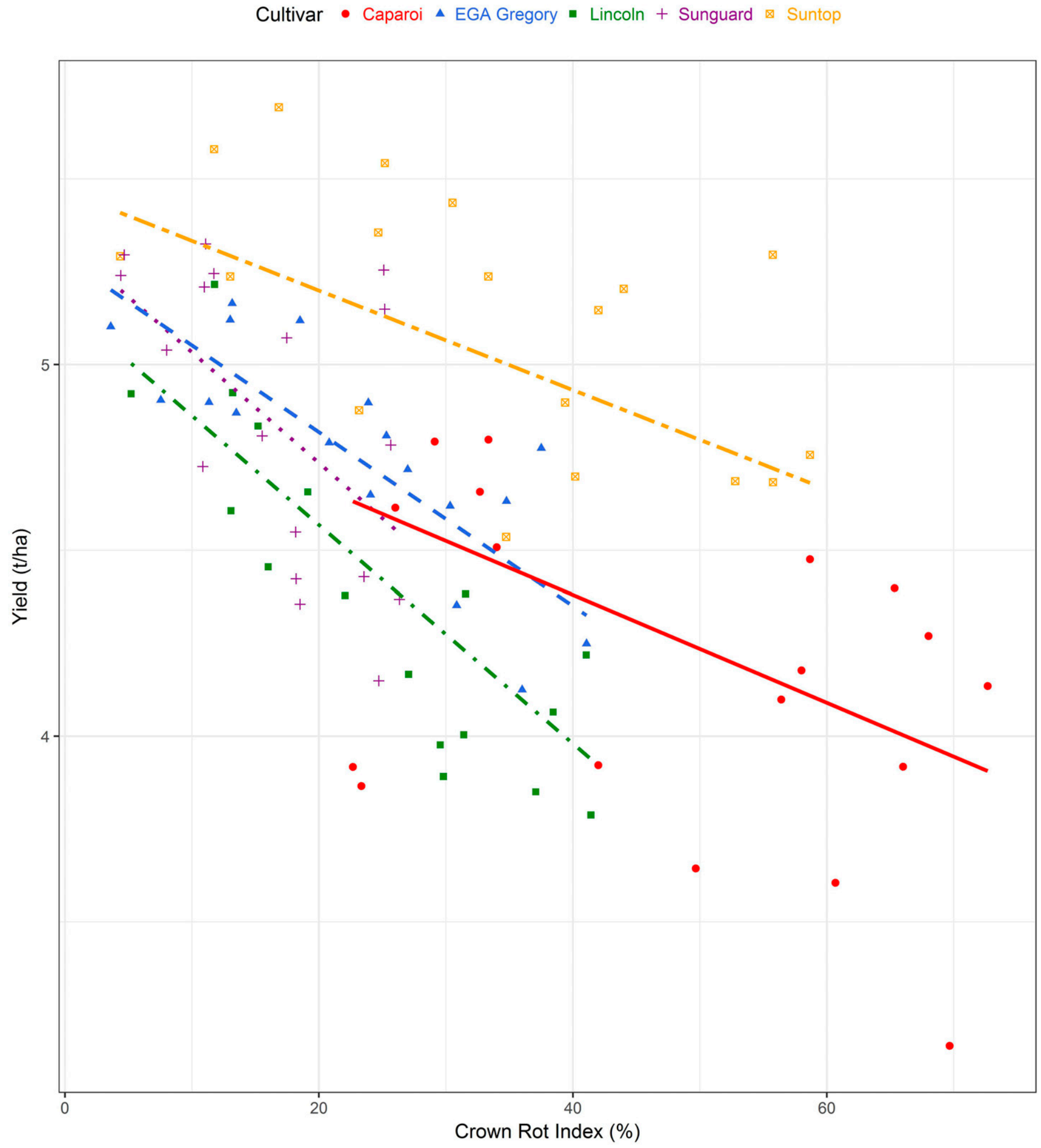

Fig. 3. Response curves describing the relationship between yield and crown rot index for five wheat cultivars in the experiment conducted near Bullarah in 2016. Symbols and lines correspond to different cultivars. 
disease and, as such, prebreeding and breeding efforts can continue to not only focus on improving the resistance of winter cereals to crown rot infection but also can select for improved tolerance to the disease. Ultimately, it is likely that both resistance and tolerance mechanisms need to be combined in future cultivars to further reduce yield losses from crown rot; a combination of mechanisms which is already being pursued by some breeding programs. This study confirms the importance of both resistance and tolerance mechanisms in reducing the extent of yield losses to crown rot, with the cultivars Sunguard and Suntop both displaying similar predicted minimum yields in the presence of crown rot infection, albeit Sunguard limited yield losses through a moderate level of resistance while Suntop restricted yield losses through a greater level of tolerance. The impact of environment will also likely play a role in the extent to which each mechanism is effective in limiting yield losses associated with crown rot, which will be a topic of future research.

\section{ACKNOWLEDGMENTS}

We thank Australian grain growers for their significant contributions through trial cooperation, the Grains Research and Development Corporation (GRDC) for its continued support, and R. Loughman (Department of Primary Industries and Regional Development) and F. Obanor (GRDC) for their constructive review of this article.

\section{LITERATURE CITED}

Alahmad, S., Dinglasan, E., Leung, K. M., Riaz, A., Derbal, N., Voss-Fels, K. P., Able, J. A., Bassi, F. M., Christopher, J., and Hickey, L. T. 2018a. Speed breeding for multiple quantitative traits in durum wheat. Plant Methods 14:36.

Alahmad, S., Simpfendorfer, S., Bentley, A. R., and Hickey, L. T. 2018b. Crown rot of wheat in Australia: Fusarium pseudograminearum taxonomy, population biology and disease management. Australas. Plant Pathol. 47:285-299.

Backhouse, D., Abubakar, A. A., Burgess, L. W., Dennisc, J. I., Hollaway, G. J., Wildermuth, G. B., Wallwork, H., and Henry, F. J. 2004. Survey of Fusarium species associated with crown rot of wheat and barley in eastern Australia. Australas. Plant Pathol. 33:255-261.

Beddis, A. L., and Burgess, L. W. 1992. The influence of plant water stress on infection and colonization of wheat seedlings by Fusarium graminearum group 1. Phytopathology 82:78-83.

Butler, D. G., Cullis, B. R., Gilmour, A. R., and Gogel, B. J. 2009. ASReml-R Reference Manual. Rep. No. Version 3. Queensland Department of Primary Industries and Fisheries, Toowoomba, Queensland, Australia.

Caldwell, R. M., Schafer, J. F., Compton, L. E., and Patterson, F. L. 1958. Tolerance to cereal leaf rusts. Science 128:714-715.

Chekali, S., Gargouri, S., Paulitz, T., Nicol, J. M., Rezgui, M., and Nasraoui, B. 2011. Effects of Fusarium culmorum and water stress on durum wheat in Tunisia. Crop Prot. 30:718-725.

De Faveri, J., Verbyla, A. P., Pitchford, W. S., Venkatanagappa, S., and Cullis, B. R. 2015. Statistical methods for analysis of multi-harvest data from perennial pasture variety selection trials. Crop Pasture Sci. 66:947-962.

Dodman, R., and Wildermuth, G. 1987. Inoculation methods for assessing resistance in wheat to crown rot caused by Fusarium graminearum group 1. Aust. J. Agric. Res. 38:473-486.

Evans, M. L., Hollaway, G. J., Dennis, J. I., Correll, R., and Wallwork, H. 2010. Crop sequence as a tool for managing populations of Fusarium pseudograminearum and F. culmorum in south-eastern Australia. Australas. Plant Pathol. 39:376-382.

Fitzmaurice, G., Davidian, M., Verbeke, G., and Molenberghs, G. 2008. Longitudinal Data Analysis. Chapman and Hall/CRC, New York.

Hogg, A. C., Johnston, R. H., and Dyer, A. T. 2007. Applying real-time quantitative PCR to Fusarium crown rot of wheat. Plant Dis. 91:1021-1028.

Hollaway, G. J., Evans, M. L., Wallwork, H., Dyson, C. B., and McKay, A. C. 2013. Yield loss in cereals, caused by Fusarium culmorum and F. pseudograminearum, is related to fungal DNA in soil prior to planting, rainfall, and cereal type. Plant Dis. 97:977-982.

Kause, A., and Ødegård, J. 2012. The genetic analysis of tolerance to infections: A review. Front. Genet. 3:262.

Kelly, A., Macdonald, B., Percy, C., and Davies, P. 2016. Selection of genotypes for resistance and tolerance to pathogens: A combined statistical analysis of yield and disease response. In: 9th Australas. Soilborne Dis. Symp. Lincoln, New Zealand.
Khangura, R. K., MacNish, G. C., MacLeod, W. J., Vanstone, V. A., Hanbury, C. D., Loughman, R., and Speijers, J. E. 2013. Current status of cereal root diseases in Western Australia under intensive cereal production and their comparison with the historical survey conducted during 1976-1982. J. Phytopathol. 161:828-840.

Kirkegaard, J. A., Simpfendorfer, S., Holland, J., Bambach, R., Moore, K. J., and Rebetzke, G. J. 2004. Effect of previous crops on crown rot and yield of durum and bread wheat in northern NSW. Aust. J. Agric. Res. 55:321-334.

Knight, N. L., Macdonald, B., and Sutherland, M. W. 2017. Colonization of durum wheat (Triticum turgidum L. var. durum) culms exhibiting premature senescence (dead heads) associated with Fusarium pseudograminearum crown rot. Plant Dis. 101:1788-1794.

Knight, N. L., and Sutherland, M. W. 2015. Culm discolouration as an indicator of Fusarium pseudograminearum biomass. Australas. Plant Pathol. 44:319-326.

Laird, N. M., and Ware, J. H. 1982. Random-effects models for longitudinal data. Biometrics 38:963-974.

Lamprecht, S. C., Marasas, W. F. O., Hardy, M. B., and Calitz, F. J. 2006. Effect of crop rotation on crown rot and the incidence of Fusarium pseudograminearum in wheat in the Western Cape, South Africa. Australas. Plant Pathol. 35:419-426.

Li, H. L., Yuan, H. X., Fu, B., Xing, X. P., Sun, B. J., and Tang, W. H. 2012. First report of Fusarium pseudograminearum causing crown rot of wheat in Henan, China. Plant Dis. 96:1065.

Liu, C., and Ogbonnaya, F. C. 2015. Resistance to Fusarium crown rot in wheat and barley: A review. Plant Breed. 134:365-372.

Liu, Y., Ma, J., Yan, W., Yan, G., Zhou, M., Wei, Y., Zheng, Y., and Liu, C. 2012. Different tolerance in bread wheat, durum wheat and barley to Fusarium crown rot disease caused by Fusarium pseudograminearum. J. Phytopathol. 160:412-417.

Lush, D. 2018. 2018 Wheat Varieties Queensland. Grains Research and Development Corporation and Queensland Department of Agriculture and Fisheries. https://grdc.com.au/_data/assets/pdf_file/0027/294750/NVTQld-Wheat-Variety-Guide-2018.pdf?utm_source=website\&utm_medium= download button\&utm campaign=pdf_download\&utm term=North\&utm content $=2018$ Wheat Variety Guide (Queensland)

Martin, A., Simpfendorfer, S., Hare, R. A., and Sutherland, M. W. 2013. Introgression of hexaploid sources of crown rot resistance into durum wheat. Euphytica 192:463-470.

McKnight, T., and Hart, J. 1966. Some field observations on crown rot disease of wheat caused by Fusarium graminearum. Queensl. J. Agric. Anim. Sci 23:373-378

Murray, G. M., and Brennan, J. P. 2009. Estimating disease losses to the Australian wheat industry. Australas. Plant Pathol. 38:558-570.

Murray, G. M., and Brennan, J. P. 2010. Estimating disease losses to the Australian barley industry. Australas. Plant Pathol. 39:85-96.

Ophel-Keller, K., McKay, A., Hartley, D., Herdina, and Curran, J. 2008. Development of a routine DNA-based testing service for soilborne diseases in Australia. Australas. Plant Pathol. 37:243-253.

Papendick, R. I., and Cook, R. J. 1974. Plant water stress and development of Fusarium [roseum] foot rot in wheat subjected to different cultural practices. Phytopathology 64:358-363.

Patterson, H. D., and Thompson, R. 1971. Recovery of inter-block information when block sizes are unequal. Biometrika 58:545-554.

Råberg, L., Graham, A. L., and Read, A. F. 2009. Decomposing health: Tolerance and resistance to parasites in animals. Philos. Trans. R. Soc. Lond. B Biol. Sci. 364:37-49.

R Core Team. 2017. R: A Language and Environment for Statistical Computing. R Foundation for Statistical Computing, Vienna, Austria.

Schafer, J. F. 1971. Tolerance to plant disease. Annu. Rev. Phytopathol. 9:235-252.

Simms, E. L. 2000. Defining tolerance as a norm of reaction. Evol. Ecol. 14: 563-570.

Simpfendorfer, S. 2016. Pages 121-124 in: Evaluation of the seed treatment Rancona Dimension as a standalone option for managing crown rot in wheat-2015. NSW DPI Northern Grains Research Results. https://www.dpi. nsw.gov.au/_data/assets/pdf_file/0007/679102/Northern-grains-researchresults-2016.pdf

Smiley, R. W., Gourlie, J. A., Easley, S. A., Patterson, L.-M., and Whittaker, R. G. 2005. Crop damage estimates for crown rot of wheat and barley in the Pacific Northwest. Plant Dis. 89:595-604.

Smiley, R. W., and Yan, H. 2009. Variability of Fusarium crown rot tolerances among cultivars of spring and winter wheat. Plant Dis. 93:954-961.

Summerell, B. A., Burgess, L. W., Klein, T. A., and Pattison, A. B. 1990. Stubble management and the site of penetration of wheat by Fusarium graminearum group 1. Phytopathology 80:877-879.

Swan, L. J., Backhouse, D., and Burgess, L. W. 2000. Surface soil moisture and stubble management practice effects on the progress of infection of wheat by Fusarium pseudograminearum. Aust. J. Exp. Agric. 40:693698. 
Thompson, J. P., Brennan, P. S., Clewett, T. G., Sheedy, J. G., and Seymour, N. P. 1999. Progress in breeding wheat for tolerance and resistance to root-lesion nematode (Pratylenchus thornei). Australas. Plant Pathol. 28:45-52.

Thompson, J. P., Clewett, T. G., Sheedy, J. G., Reen, R. A., O’Reilly, M. M., and Bell, K. L. 2010. Occurrence of root-lesion nematodes (Pratylenchus thornei and P. neglectus) and stunt nematode (Merlinius brevidens) in the northern grain region of Australia. Australas. Plant Pathol. 39:254-264.

Thompson, J. P., Owen, K. J., Stirling, G. R., and Bell, M. J. 2008. Root-lesion nematodes (Pratylenchus thornei and P. neglectus): A review of recent progress in managing a significant pest of grain crops in northern Australia. Australas. Plant Pathol. 37:235-242.

Trudgill, D. L. 1991. Resistance to and tolerance of plant parasitic nematodes in plants. Annu. Rev. Phytopathol. 29:167-192.

Tunali, B., Nicol, J. M., Hodson, D., Uçkun, Z., Büyük, O., Erdurmuş, D., Hekimhan, H., Aktaş, H., Akbudak, M. A., and Bağci, S. A. 2008. Root and crown rot fungi associated with spring, facultative, and winter wheat in Turkey. Plant Dis. 92:1299-1306.

van den Berg, F., Paveley, N. D., Bingham, I. J., and van den Bosch, F. 2017. Physiological traits determining yield tolerance of wheat to foliar diseases. Phytopathology 107:1468-1478.

Verrell, A. G., Simpfendorfer, S., and Moore, K. J. 2017. Effect of row placement, stubble management and ground engaging tool on crown rot and grain yield in a no-till continuous wheat sequence. Soil Tillage Res. 165:16-22.

Wallwork, H., Butt, M., Cheong, J. P. E., and Williams, K. J. 2004. Resistance to crown rot in wheat identified through an improved method for screening adult plants. Australas. Plant Pathol. 33:1-7.

Wildermuth, G. B., and McNamara, R. B. 1994. Testing wheat seedlings for resistance to crown rot caused by Fusarium graminearum group 1. Plant Dis. 78:949-953. 